\title{
The significance of tasks in second language learning: The case of Africa University in Zimbabwe
}

Emmaculate Mvundura ${ }^{1}$, Paul Svongoro ${ }^{2 *}$

Department of Humanities, Africa University, Mutare, Zimbabwe $e^{1,2}$

mvundurae@africau.edu ${ }^{1}$,svongorop@africau.edu ${ }^{2 *}$

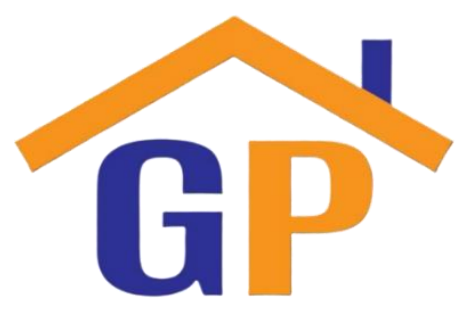

Article History

Received on 15 July 2021

$1^{\text {st }}$ Revision on 2 August 2021

$2^{\text {nd }}$ Revision on 17 August 2021

Accepted on 20 August 2021

\section{Abstract}

Purpose: This study utilised the case study approach for an indepth understanding of the practices of teaching English as a Second Language (ESL) at Africa University (AU), Zimbabwe. The study aimed to provide a description of unique and typical ESL experiences in a particular African context.

Research Methodology: The study investigated 60 participants who were prospective undergraduate students enrolled in the ESL programme and were separated into two groups. Each group consisted of 30 participants who received task-based instruction hinged on reading, writing, listening, and speaking.

Result: An analysis of the learners' performance revealed that tasks facilitate the learning of ESL by exposing learners to different problem-solving scenarios that required higher-order cognitive skills.

Limitations: This study was based on the ESL classroom at AU, which enrols students from African countries. A similar study could be conducted with students from more diverse backgrounds to establish if the results of this study could be corroborated or refuted. Similar studies could also be conducted in other second language contexts where English is not the target language.

Contribution: The results of this study are important for the discipline of ESL as they support existing knowledge that tasks allow learners to communicate using the correct grammatical structures in a given relevant context.

Keyword: Communicative language teaching, Task-based approach, Target language

How to cite: Mvundura, E., \& Svongoro, P. (2021). The significance of tasks in second language learning: The case of Africa University in Zimbabwe. Journal of Social, Humanity, and Education, 1(4), 297-307.

\section{Introduction}

The teaching and learning of English as a Second Language (ESL) have experienced modifications in the $21^{\text {st }}$ century based on the Communicative Language Teaching (CLT), and the Task-based Learning and Teaching (TBLT) approaches. The modifications have witnessed a shift from the previous emphasis on the mastery of linguistic forms such as grammar and morphology to a focus on English as means of communicative competence and negotiation of meaning. These new approaches to the teaching of ESL emphasise the mastery of the four macro skills compared to grammatical competence, which dominated the $19^{\text {th }}$ and $20^{\text {th }}$ centuries. As a result, teachers now rely on current ESL teaching trends embedded in these two approaches. The task-based approach, for instance, is regarded as a unique model of the CLT approach, which considers real meaningful communication as a major characteristic of language learning (Willis \& Willis, 2007; Richard \& Rodgers, 2001). Learners increase and improve their language proficiency by exposing real-life tasks in the teaching 
and learning environment. The main thrust is hinged on communicative competence and grammatical competence to negotiate meaning, convey ideas, or express thoughts and feelings. Learners should be exposed to adequate scenarios to use the target language in tasks located in real-life situations rather than in abstract situations. The idea of working within set parameters or prescribed rules is discouraged in the teaching and learning of ESL.

The main objective of this chapter is to examine the characteristics of TBLT and explore the benefits of this approach to ESL learners in general and at Africa University (AU) in particular. Task-based language teaching and learning is a learner-centred approach that is assumed to offer more benefits to learners. TBLT demands more interactive or collaborative learning because of its hands-on skills development (Skehan, 1996). The CLT approach addressed the shortcomings of grammar-translation, direct method, and audio-lingual methods that dominated language teaching in Europe in the $19^{\text {th }}$ century. Activities involved repetition, memorisation, and translation of sentences from English to native language vice-versa. Prabhu (1997) coined the idea of using tasks in the ESL classroom, which was a reaction against the traditional teaching of English as a Foreign Language (EFL) in India and not sparing the kind of CLT used in India during that time. Language learning is seen as a process of learning both the rules and the application of the rules rather than focusing on the communicative use of the language.

In other words, CLT teaches a language, not the rules that govern the structures to be learnt or mastered. The level of engagement among learners, due to tasks, triggers motivation since some of the activities are based on real-life experiences, thereby promotes both language acquisition and learning.

\section{Background of the study}

In Zimbabwe, some teachers are still not familiar with the task-based kind of instruction or its implementation within current approaches. Therefore, training is necessary for teachers to familiarise themselves with the $21^{\text {st }}$ teaching methodologies and the procedures involved in implementing the phases involved in an ESL classroom that utilises task-based learning. Students should be informed about task-based learning, the tasks, their aims, and what they are expected to do in a task-based instruction environment.

Changing the teacher's mindset is crucial because teachers trained between the 19th and 20th centuries received training focused on traditional approaches; hence, a smooth transition is required. The learners should be exposed to language input which enables them to produce different forms or structures, unlike in the traditional class where the teacher knows all. To produce the desired outcome in the ESL classroom, learners should play a significant role in the learning process for them to learn the target language. Thus, the teacher becomes a facilitator or a manager of the activities taking place in the classroom. The focus is on closing the gap in communication by giving communicative tasks that require a learner to act to develop meaning through collaboration. This allows learners to generate more words and sentences, thereby closing the communication gap. Tasks should be grounded in different contexts that promote sociolinguistic competence, grammatical competence, and communicative competence (Canale \& Swain, 1980) to develop language that suits the environment. This outcome is achieved through exposing learners to topics such as shopping, job interviews, visiting a doctor, including many other problem-solving activities.

Delivery of lessons poses some problems since the curriculum emphasises the CLT approach, but the implementation is overshadowed by the need to complete the syllabus in preparation for examinations. As a result, this forces lecturers to resort to teacher-centred approaches to finish the syllabus's requirements. It is a big challenge to most teachers since they are not equipped with the relevant skills to implement the tasks in the teaching and learning process because much time is required to carry out the tasks. The focus is on accuracy rather than fluency and complexity. The University should consider revising the ESL curriculum to address the needs of the learners, thus equipping them with skills for use in the real-world context. This will improve the learners' proficiency since they are exposed to real communication using French and Portuguese. Teachers should enrich the University curriculum with task-based instruction for the benefit of the learners. The researchers in this paper 
propose that teachers undergo in-service training to familiarise themselves with task-based instruction since most of them were trained during a period when traditional methods such as grammartranslation and audio-lingual methods were still popular.

\section{The aim}

This chapter aims to examine the effectiveness of task-based learning in the Intensive English class at AU. The Intensive English programme is a pre-university requirement for prospective students enrolled from non-English speaking countries who wish to be enrolled on the main degree programmes at AU. The Intensive English Unit adopted task-based teaching and learning to increase grammatical and communicative competence among these international students. In other words, the Unit selected this approach after considering the students' level of proficiency since most of them operate in the pre-elementary and elementary stages. Task-based teaching creates a language learning environment that exposes learners to various meaningful activities to facilitate the negotiation of meaning in different communicative situations, both inside and outside the classroom. The nature of this approach involves real-life situations concerning the context or environment where the task is placed. Exposing learners to various learning situations encourages the learners to acquire more grammatical structures necessary in the communicative task through reading, speaking, listening, and writing.

This chapter, therefore, aims at exploring the effectiveness of the task-based approach and how taskbased learning could be used to promote the learning of ESL in the Intensive English Class at AU. This broad aim will be explored through the following research questions:

a) How do tasks (i.e. real-life scenarios) enhance students' learning in the ESL classroom at AU?

b) Are the outcomes or performances of the students a true reflection of the effectiveness of task-based learning in the ESL class at AU?

\section{Statement of the Problem}

The task-based approach was introduced after considering the plight of some non-English speaking AU students, vis-à-vis their academic performance in assignments and examinations. The students from non-English speaking countries experience difficulties in comprehending what they have read, and as a result, poor performance in both written and oral work is recorded. The learners lack metalinguistic skills such as phonological and morphological awareness and orthographic knowledge of the English language, which is vital in learning a new language. It was noted that most of these students lacked proficiency in the target language hence the prerequisite to enhance the four macroskills before they could enrol in their respective degree programmes. This study investigates the effectiveness of tasks in acquiring a new language and establishes whether: (1) it is beneficial to ESL learners at AU and; (2) it helps address some of the challenges ESL learners face in learning a second language.

\section{Literature review}

\section{Tasks in second language learning}

There is abundant literature on second language learning and the task-based language teaching approach. This literature has explored the importance of learning English as a second language and the usefulness of the task-based language teaching and learning approach in various contexts.

Seyedi and Farahani (2014), for instance, researched whether traditional writing contributes to the development of reading comprehension. The study tested two groups of female students: one group received task-based instruction while the other received traditional instruction. The findings established that task-based writing contributed significantly to the reading comprehension of EFL Iranian learners, whereas traditional writing instruction was not an effective way to improve reading comprehension. In other words, tasks equip learners with the skills required to process a text and make sound judgments and evaluations. The study concluded that learners participate through collaboration, which involves interacting with authentic scenarios to learn reading and writing. 
Ganta (2015) established that some elements are overlooked in the traditional language teaching approaches when learning a second language. Ganta's study argued that learners are exposed to grammatical structures compared to language resources specific to the target language and that tasks help learners acquire the target language through practical activities. In this study, Ganta (2015) agrees with Prabhu (1987) that task-based learning is more interactive and limits rote learning activities in acquiring knowledge of the target language. In conclusion, Ganta's study reached that tasks boost intrinsic motivation through collaboration and the willingness to learn more concerning the target language when learning a second language.

Another interesting study is that of Nunan (2004). Nunan (2004) observed that learners are required to understand the learning materials which emphasise real-life situations. The learning materials improve the use of language, and teachers should equip the learners with the basic information concerning the use of the learning materials to promote interaction among themselves. Teachers should distinguish between knowledge-constructing tasks and knowledge-activating tasks. Knowledge-construction tasks involve building knowledge to develop comprehensible output (Samuda, 2001 cited in Skehan, 2003). Teaching methods should equip the learners to identify gaps in the output the teacher makes available the language to close the gap (Swain,1995 cited in Skehan, 2003). Swain is concerned with the ability of a student to notice the gap. In other words, tasks help learners build new language structures based on the input to close the gap.

While the above studies were conducted in non-African contexts, they provide fascinating insights that help shape this study. However, what is interesting about the studies cited above is that the ESL classrooms the researchers' studies were almost homogeneous. The learners were from the same culture. As indicated in the introduction of this study, students in the Intensive English classroom come from different African countries, making this ESL classroom heterogeneous. Therefore, the current study explores the extent to which tasks assist learners in a heterogeneous classroom acquire the target language. In the sub-headings below we further analyse the literature regarding the role tasks play in learning a second language.

\section{Definition of a task and Task-Based Language Instruction}

A task is defined as a work plan that requires learners to process language pragmatically to achieve an outcome that can be evaluated regarding whether the correct or appropriate proposition has been conveyed (Ellis (2003) cited in Ganta, 2015). Furthermore, Ellis (2013) describes tasks as work plans that provide learners with materials to achieve a desirable outcome specified in communicative rather than linguistic terms. In addition, tasks or activities should satisfy the following criteria to produce the desired outcome; focus on meaning initially; set up a goal to work towards; evaluate that outcome and relate to the real world (Widdowson, 2003). In support, (Ellis (2003), cited in Seyedi \& Farahani (2014: 229), acknowledges that a task is a work plan whose primary focus is on meaning. A task involves real-world processes of language use and involves the four language skills. A task engages cognitive processes and has a clearly defined communicative outcome. In support of this, a task must be meaning-focused, have a gap, require that learners use their resources and have a tangible outcome (Ellis (2009) cited in Baralt \& Gomez, 2017). Thus, completion of these activities is influenced by the ability to negotiate meaning in the communicative process to produce the desired outcome. Basically, in the ESL classroom, the outcome is essential to determine the effectiveness of the instruction. Thus, careful selection of tasks in the teaching and learning planning process plays a significant role since it can be a setback or drawback in the learners' performance or competence. Tasks equip learners with comprehending, manipulating, producing or interpreting skills necessary in learning the target language (Ellis (2009) cited in Ganta, 2015).

Cognitive processes such as selecting, reasoning, classifying, and sequencing information from one form of representation to another play a pivotal role in putting the task into practice (Ellis, 2003). In other words, to complete the task, both explicit and implicit learning should occur through guided and free activities for language development. Thus, learners know the structure of words, use them in different contexts, deduce word meanings, and link them to other words. Tasks influence creativity in language usage through vocabulary knowledge and reading comprehension, and the ability to 
contextualise the task enhances effective decoding and understanding of the English language. In other words, vocabulary knowledge, phonemic awareness and morphemic awareness reinforce the ability to understand and manipulate the phonemes and morphemes in both written and spoken language through the application of relevant tasks.

Ganta (2015) defines task-based language teaching as classroom activities that provide rich support to enable students to apply grammatical knowledge into the communicative task(s). Task-based language teaching is viewed as a learner-centred approach to teaching contrary to teacher-dominated approaches (Van Den Branden 2016). Ellis \& Shintani (2014), cited in Van Den Branden (2016), define TBLT as an approach that focuses on developing the learners' communicative competence by engaging them in meaning-focused communication through carrying out the tasks. In addition, taskbased language teaching is regarded as a pedagogical framework for the theory and teaching of second or foreign languages (Baralt \& Gomez, 2017). A task-based environment is supported by tasks that enable learners to process information through collaboration. In addition, exposing learners to a wide range of input and output improves vocabulary knowledge and word recognition abilities to promote reading, writing, listening and speaking skills. A task-based classroom ensures that learners are provided with meaning rich tasks to show that they can use the language in real-life contexts to produce an outcome. Tasks such as job interviews and making a room reservation require the language for learners to produce a communication outcome. Thus, Nunan (2005) views a task as a piece of classroom work focusing on transmitting meaning rather than manipulating forms. In agreement, the researchers believe that oral and written assessment plays a major role in the teaching and learning process since learners are assigned tasks that test both grammatical competence and communicative competence, thus identifying forms and their role in communication.

\section{Advantages of the Task-based Language Teaching approach}

Task-based learning facilitates prompt interaction and enables learners to use the grammar and vocabulary acquired from job interview activities. In addition, learners are motivated to solve problems without asking for help from the teacher, thereby promoting independent learning. The interactive activities provide a rich environment for learners to practice the language through real-life contexts. The teacher should give minimal help for learners should satisfy the exit competencies (Ellis, 2013). Furthermore, motivation and enjoyment are crucial elements in an ESL classroom because they are an active ingredient of collaborative learning in the learner-centred environment within a taskbased classroom. These two elements can boost creativity among learners, and as a result, learners explore various strategies to master the target language. This increases the level of both communicative and grammatical competencies for use in the real world. In addition, tasks mainly focus on participatory activities which permit students to interact in groups or pairs. The participatory activities assist in learning new vocabulary through guessing word which is related to the topic under study, for example, making a reservation at a hotel (Nunan, 2004). Learners are encouraged to come up with a list of words without help from the teacher. They should constantly revise the newly acquired vocabulary to negotiate meaning in different situations.

Learners are encouraged and supported by the teacher to work together for task completion. As such, positive interdependence, social integration, and learning can increase (Ellis 2003). Classroom scenarios that promote motivation maximise the level of communication in the ESL classroom. This helps learners to comprehend the content while carrying out the task. A strong foundation is built, and learners are equipped with various skills by performing different scenarios, equipping them with the language for educational and public use. Learners develop the ability to use the language in real-life situations, which empowers learners with fluency and accuracy.

Interaction between learners and other learners, learners and teachers, task aid materials and teachers' support is integral to task-based settings (Nunan, 2004; Ellis, 2013). This promotes language competence and learning motivation of second language learners, especially those who lack confidence in English communication. In other words, learners are encouraged to participate in task activities in a task-based classroom, and they should be active rather than passive. Learners' confidence is boosted through experiential learning compared to traditional methods where the 
teacher knows all, thereby prohibiting learning through sharing experiences (Ganta, 2015; Van Den Branden, 2016).

\section{Disadvantages of Task-based Language teaching}

Students used to a robust teacher-centred learning style may become demotivated by classroom activities that do not resemble formal classroom learning rather than motivated by the student-centric aspects of task-based instruction (Burrows (2009) cited in Dickinson 2010). Task-based instruction can be demotivating for students who are used to learner-centred learning. Learners end up putting little effort since the focus is on passing the exam rather than communicative competence. Focus on passing the exam is what Ganta (2015) calls survival orientation compared to achievement orientation to accomplish the desired outcome. Learning progress in task-based instruction depends on student input. However, it is not possible to develop and learn those structures which learners do not attempt to use (Ellis 2003).

Considering the students' background in the ESL classroom at AU, communicative competencies should be developed to communicate in different environments. These learners are not only learning a language for academic purposes but also communicating with the outside world. By so doing, taskbased instruction equips the learner with both grammatical and communicative competence, thereby promoting metalinguistic skills. Therefore, the researchers concur that oral and written assessment in task-based instruction plays a significant role in the teaching and learning process through tasks for learners to work on the target language to produce the desired outcome. The Intensive English programme at $\mathrm{AU}$ embraces a curriculum that considers both grammatical and communicative competence to benefit these ESL students since their future is governed by their ability to showcase the four language macro-skills: reading, writing, speaking and listening.

\section{Conceptual framework}

The study is grounded on Nunan's (2004) six-step procedure. The procedure captures what learners are expected to do during the learning process. In other words, learners are required to select a specific real-life context in which they can use language. In the case of this study, the job interview and other contexts were used as an example in following the six-step procedure.

The first step is in the procedure is called schema building. This step is meant to draw on the learner's background knowledge to introduce the topic, for example, the job interview scenario. This enables learners to share different experiences they may come across when being interviewed for a job.

The second step is controlled practice. The controlled practise provides learners with guided practice in using the target language vocabulary, structures and functions. The teacher gives a working sample of a job interview to the learners to participate in the actual conversations and is free to ask questions based on three job interviews, e.g., interview for a teacher, a nurse and a shop attendant. Learners are required to go through the job interview without referring to the given sample and are required to use their new vocabulary. This involves identifying root words from the sample interview and manipulating them by listing the inflected and derived forms to increase their vocabulary knowledge. The spelling activities are introduced to minimise errors and violations of rules and wrong substitutions of letters within words.

The third step is authentic listening meant to provide learners with intensive listening practice. Students must listen to the job interview session from an audiotape or watch a video clip focusing on the job interview. They are expected to collaborate in pairs or groups when going through the interview session. In other words, the audio-lingual method takes centre stage since it pays attention to both listening and speaking competencies. Phonological awareness also comes into play, and as a result, learners practice the desired pronunciation of words in the target language.

The fourth step is to focus on linguistic elements. It is meant to make learners practice using one/more linguistic elements. Learners are expected to ask and answer questions focusing on the job interview and use conjunctions, coordinators, and discourse markers such as, likewise, otherwise, however, 
despite, to present their opinions or facts logically. The parts of speech are vital because learners should use the correct tenses during the job interview activities. The breaking down of words into smaller units such as morphemes and phonemes enables learners to decode and encode words and sentences in the given task.

The fifth step is meant to provide freer practice. Freer practice requires learners to use the target language to complete tasks in pair/group work. The learners are now required to fill in the gaps using their language, and they should be able to negotiate meaning. Gap filling requires them to produce more comprehensible output, and comprehending important ideas after reading or during the reading process is very significant. Learners are exposed to problem-solving tasks, which allow them to deduce meanings of known and unknown words to increase their vocabulary.

The last step is when the teacher can then introduce pedagogical tasks and provides the learners with feedback. The learners are asked to develop their own job interview sample questions and responses in groups using authentic language. The learners are encouraged to showcase authentic vocabulary and grammar in job interview sessions during this activity. In other words, this facilitates correct word spelling and processing the structure of complex words in their working memory.

\section{Research methodology}

This chapter is a practical example of descriptive research. It uses the case study approach for an indepth understanding of the practices of teaching ESL to non-English speaking beginners at AU. The goal is to provide a description of unique and typical experiences in a particular context which is AU (Hancock \& Algozzine, 2006). The case was made up of 60 participants who were prospective undergraduate students who enrolled for the Intensive English programme and were separated into two groups. Each group consisted of 30 participants who received task-based instruction hinged on reading, writing, listening and speaking activities. The course is solely content-based and uses a prescribed textbook English File: pre-elementary and elementary workbook as the basis for classroom work. The Intensive English language classes were conducted for five hours per day and were thirteen weeks long when the study was carried out.

Data collection activities included audio and video recordings on activities and tasks such as job interviews, shopping, calling customer service and visiting a doctor. These activities were employed to develop learners' listening, speaking, reading and writing skills. The TBLT approach provided guidelines that helped the researchers account for the approach's effectiveness in the teaching and learning ESL at AU.

In order to achieve the objectives of the study, a diagnostic test was administered for placement purposes at the beginning of the study. The learners were placed in pre-elementary and elementary groups after the test. After that, tests for reading, writing, speaking, and listening were administered to examine the learners' level of proficiency. Audios and worksheets mainly derived from the learners' main resource book mentioned above were used in teaching and learning. Data were also collected through interviews and participant observations, where one of the researchers was a participantobserver throughout the study.

The collected data were then presented according to the six-step procedure proposed by Nunan (2004) explained above. The following topics formed the basis of the lessons:

1) Visiting a doctor;

2) Conducting interviews;

3) Shopping;

4) Calling customer service for help;

5) Ordering food in a restaurant and

6) Weather forecast. 


\section{Findings and discussions}

In response to the study's research questions, the findings revealed that TBLT and learning are crucial in the ESL classroom because learners collaborate and interact independently without too much teacher interference. Learners were directly involved in problem-solving tasks, thereby nurturing or fostering valuable skills to promote grammatical and communicative competence. The four language skills were developed through the use of relevant tasks in the ESL classroom. The focus was on reading, writing, listening and speaking, and the most difficult one is writing. Learners were exposed to controlled practice activities that involved writing ranging from words, sentences, paragraphs and compositions. The learners appreciated the use of tasks in learning a second language, as illustrated and discussed in the following sections.

\section{Findings from listening activities}

Listening activities facilitated both verbal and non-verbal communication. Learners were required to listen and respond, including reading different texts from newspaper articles and short stories in the workbook. The learners experienced spelling difficulties which resulted from sound and pronunciation challenges as well as the sound-letter correspondences. For instance, the letter $\mathbf{c}$ is pronounced with a $/ \mathrm{k} /$ sound as in coat or/s/ sound in the city. Three students commented that:

Listening activities helped them deal with new words' sounds, especially at the beginning, middle, and end of a word.

The learners confirmed that listening activities assisted them to deal with spelling problems they encountered in the first four weeks of the programme and further indicated that collaborative learning was fundamental when learning a second language. However, they agreed that the listening activity instructions should be clear to avoid confusion when completing the task.

Regarding listening activities, students also observed that some of the consonants are silent when pronouncing some of the words; for example, the letter $\mathbf{h}$ is silent when pronouncing it in French. It starts with a vowel sound instead of a consonant sound.

The teaching of homophones through listening activities enabled learners to visualise and listen, thereby facilitating the grouping and sorting of words in their respective parts of speech. One learner said that visualising and listening to sounds enhanced his spelling skills, especially when comparing and contrasting confusing words. The learners were able to role-play the difference between die and dye, saw and sow. One learner highlighted that those short performances helped her communicate with her partner using the homophone in different contexts. Tasks with the following homophones were given to learners to use the words in different contexts: allowed-aloud; fair-fare; heard-heard; waist-waste. Another student had this to say:

It was initially challenging to communicate or interact with fellow Zimbabwean colleagues because of pronunciation problems. However, after the exposure to listening tasks, I now have the confidence and courage to start conversations. The influence of French when speaking is no longer a challenge to me.

Three learners also agreed with their colleagues when they said that these activities increased their vocabulary, and the chances of supplying wrong spellings were now minimal. However, students from Portuguese speaking countries experienced difficult times with the pronunciation of homophones, let alone the spellings. The researchers showed them videos of cartoons like Tom and Jerry to improve their vocabulary.

\section{Findings from writing activities}

The four language skills were developed through the use of tasks in the ESL classroom. The focus was on reading, writing, listening and speaking, and the most difficult one was writing. Learners were exposed to controlled practice activities that involved writing ranging from sentences, paragraphs and compositions. The results revealed that learners prefer to work in pairs or small groups of four to understand better the concepts being taught. Two students agreed that teamwork helped us assist each other and compare possible solutions to their paragraph and essay writing problems. Another student 
expressed that "the knowledge of sentence types is critical in the writing process because it equips learners with various skills when constructing and transforming sentences. The learner confirmed that: I now know the difference between simple and compound sentences, and this was facilitated by the use of dialogues where I used different sentences in different contexts. I was exposed to such activities as making telephone calls, making a reservation in a hotel and applying for a place to study in a university. I can now transform simple sentences into compound sentences that still carry the same meaning as the simple ones.

One student commented that reading comprehension has helped him to infer word meanings from the passage. She highlighted that:

When I come across a new word in a reading passage, I go through it several times with my friends and then look at the words around it to develop the contextual meaning. We may look for the meaning in the dictionary. However, teamwork encourages developing inference skills and it is exciting to know a word and its meaning and, after that, construct sentences using the new words. This will help us when writing about our experiences in life because of the newly acquired vocabulary.

Scaffolding activities helped learners to start from simple to complex concepts without serious problems. Three learners were of the opinion that:

It is easy to construct a simple sentence and use it in a conversation or dialogue, for example, when exposed to shopping vocabulary. However, the most exciting thing is to join the two sentences, which make a compound sentence and come up with new words to replace some of the clauses.

Written work in the form of tests and end-of-semester examinations revealed that the ability to manipulate morphemes into words is still limited in most learners due to limited vocabulary. For example, some students wrote, "I walks to town every day*; She like the drink very much*; We sleep two weeks in hotel*. The introduction of communicative tasks proved to be fruitful due to indoor and outdoor activities. Through the use of work sheets and games where learners were asked to describe people, objects and places motivated them to want to learn more or describe more things. The concept of comparative and superlative adjectives was difficult because of the rules in forming comparatives and superlatives. It was also noted that irregular adjectives were difficult to understand; for example, one student wrote, "good, gooder, goodest*" as the comparative and superlative forms of good instead of good, better, best. The long adjectives such as expensive, responsible, beautiful and advanced were complex. As a result, most learners came up with comparatives like expensiver, beautifuler* when comparing two things. This resulted from the complex morphological forms, which are based on the ability to inflect and derive words from the root words.

\section{Findings from reading activities}

Reading is a difficult task in the ESL classroom, and most learners are not comfortable with reading exercises. One learner expressed that reading is not her favourite because of spelling and pronunciation problems associated with reading. Through exposure to a variety of reading texts which were relevant to their areas of study in their intended degree programmes, learners were motivated to read. Four learners believed that visual representation in pictures and video clips provided a strong foundation when learning to read in a second language. The description of main ideas and characters encouraged understanding of the texts read. Five students revealed that summarising actions performed by characters and role-playing them promotes their understanding of the text or reading passage and further assisted the learners to present ideas logically. Interacting with words only without sound and visual images is not ideal in the ESL classroom because of how some of the words are pronounced, for example, words like umbrella and uniform. Thus, the vowel and consonant sounds at the beginning of the two words are confusing to ESL learners. Pictures and sounds are critical drivers in listening activities as they promote mastery of the English sound system. The ability to map sounds and letters is crucial when one is learning a new language. 
Reading is regarded as the ability to identify letters ad sounds, linking them together to form words and sentences hence the need to read and comprehend the meanings of new words and ideas, interpret, evaluate and make some judgements from the read passage or story. Learners mastered the skills of skimming and scanning during the reading sessions. The learners displayed the ability to scan a text to get the idea behind the story and read to respond to comprehension questions. These skills developed over three months. Ten learners were of the opinion that, "Reading is a difficult task but comprehending what is in the text is aided by the knowledge of letters and sounds of different words in a given text." One of the students reported, "I can make judgements after reading a text by connecting ideas to my previous knowledge to achieve the desired outcome."

Making judgements is a high-order skill that enables individuals to increase the ability to understand and develop their language skills. In other words, a solid morphological awareness is an essential component of linguistic knowledge since morphemes have semantic, phonological, and syntactic properties that clearly express the role of a particular word in its linguistic form.

\section{Findings from remedial sessions}

Remedial sessions were carried out after normal class time. The sessions focused on the usefulness of task-based instruction in ESL. The learners were exposed to a rich learning environment influenced by interactive methodologies, which proved to be a source of motivation because of the teachers' hands-on approach and extra attention. Most of the students agreed that tasks promote the development of the four language skills essential in students' academic life. Involving learners in writing activities also helped improve the other skills since they are inter-woven, leading to effective language learning. The level of participation was triggered by the desire to produce the outcome, which was assessed at the end of the program.

The lack of metalinguistic skills, including phonological awareness, morphological awareness, and orthographic knowledge, hindered the mastery of the four language skills in an ESL classroom. For instance, learners from Portuguese-speaking countries proved that their orthography is different from English orthography, which highly affected the structure of syllables, phonemes, and morphemes learned in the target language. Some teachers assumed that the ESL learners could read and write, which contributed to the kind of pedagogic instruction used in the classroom for both slow and fast learners. There is a need to develop tasks that require learners to acquire the language and know the purpose of the structures and forms in a language. The integration of reading and writing skills, speaking and listening skills are developed by applying meaningful real-life and pedagogic tasks in an ESL classroom to produce a better crop of students meant for degree programmes at AU despite the multi-cultural dimension.

\section{Implications for ESL teachers}

The study confirmed that it is important for teachers to introduce tasks that enable learners to correctly organise what they have learned by grouping comparative and superlative adjectives. Teachers should create a conducive learning environment to promote collaboration and interaction among learners and the teacher by asking questions and reading and listening to different texts. Collaborative learning becomes a significant way of learning a second language through exposure to comprehensible input from their peers; thus, teachers should provide active engagement (cognitive and social) opportunities and contextualise the tasks with real-life examples to promote acquisition.

Teachers are expected to help learners realise the relationship between words, sounds, and structures to infer meanings from the surrounding context and their background knowledge. For example, after reading a story, they should develop contextual meanings of words used in the passage instead of a dictionary meaning. The teacher should encourage learners to experiment with different ways of creating and using language through playing language games and word puzzles. Both comprehensible input and output play an important role in the language learning process so that the teacher monitors progress for scaffolding purposes. The teacher should be prepared to guide the interactions and direct the activities happening in the class. 


\section{Conclusion}

The present paper investigated the effectiveness of task-based instruction in an ESL classroom at Africa University. The study established that tasks facilitate learning a second language by exposing learners to different problem-solving scenarios that required higher-order cognitive skills. The results of this study support existing knowledge that tasks allow learners to communicate using the correct grammatical structures in a given relevant context. The results revealed that tasks increased vocabulary knowledge, word reading and reading comprehension in learners, and as a result, the awareness of the four macro skills are developed. The Intensive English learners at Africa University appreciated the TBLT, and its effectiveness was realised through their performance in both written and oral activities. Teachers should use tasks to promote the acquisition of the target language through interaction.

\section{Limitations of the study}

This study was based on the ESL classroom at Africa University in Zimbabwe. Africa University generally enrols students from African countries. A similar study could be conducted with students from more diverse backgrounds to establish if the results of this study could be corroborated or refuted. Similar studies could also be conducted in other second language contexts where English is not the target language. Such second language

\section{References}

Canale, M., \& Swain, M. (1980). Theoretical Bases of Communicative Approaches to Second Language Testing. Applied Linguistics, 1, 1-47. http://dx.doi.org/10.1093/applin/1.1.1

Baralt, M., \& Gómez, J. M. (2017). Task-based language teaching online: A guide for teachers. Language Learning \& Technology, 21(3), 28-43.

Ellis R. (2003). Task-based Learning and Teaching. Oxford: Oxford University Press.

Ellis, R. (2013). Task-based language teaching: Responding to critics. University of Sydney Papers in TESOL, 8, 1-27.

Ganta, T.G. (2015). The strengths and weaknesses of the task-based learning (TBL) approach. Scholarly Research Journal for Interdisciplinary Studies, Vol-iii/xvi. 2760-2771.

Dickinson, P. (2010). Implementing task-based language teaching in a Japanese EFL context. Centre for English Language Studies Postgraduate Programmes. The University of Birmingham, UK.

Hancock, J., \& Algozzine, B. (2006). Doing a Case Study Research: A Practical Guide for Beginning Researchers. New York: Teachers College Columbia University Press.

Nunan, D. (2004). Task-based language teaching. Cambridge: Cambridge University Press.

Prabhu, N. (1997). Second Language Pedagogy. Oxford: Oxford University Press.

Richards, J., \& Rodgers, T. (2001). Approaches and Methods and Language Teaching. Cambridge: Cambridge University Press.

Seyedi, H., \& Farahani, A.K. (2014). The Application of Task-based Writing and Traditional Writing on development of Reading Comprehension of Advanced Iranian Learners. International Journal of English language education. V2(1):225. http://doi.org:10.5296/ijele.v2i1.5330

Skehan, P. (2003). Task-based instruction. Language Teaching, 36, 1-14.

Van Den Branden, K. (2016). The Role of Teachers in Task-Based Language Education. Annual Review of Applied Linguistics, Vol 36, 164-181.http://doi.org/10.1017/S0267190515000070

Widdowson, H.G. (2003). Defining issues in English language teaching. Oxford: Oxford University Press.

Willis, J., \& Willis D. (2007). Doing Task-Based Teaching. Oxford: Oxford University Press. 